\title{
EFFECT OF TURNING PARAMETERS ON METAL REMOVAL AND TOOL WEAR RATES OF AISI 1018 LOW CARBON STEEL
}

\author{
C. Mgbemena ${ }^{1,}{ }^{*}$, C. Mgbemena ${ }^{2,+}$, G. Etebenumeh ${ }^{3}$ and F. Ashiedu ${ }^{4}$ \\ 1,3,4 Department of Mechanical Engr., Federal Univ. of Petroleum Resources, EFFurun, Delta State, NigERIA \\ + Department of Industrial/Production Engr., NnAmdi AZIKIWE University, AWKa, ANAmbra State, NigERIA

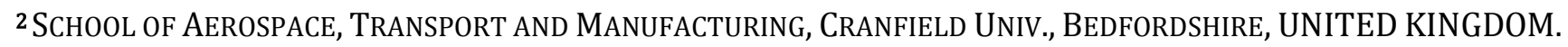 \\ E-mail addresses: ${ }^{1}$ mgbemena.ogonna@fupre.edu.ng, 2 ce.mgbemena@unizik.edu.ng, ${ }^{3}$ gadwindpius@gmail.com, \\ 4 ashiedu.ifeanyi@fupre.edu.ng
}

\begin{abstract}
The quality of machined parts and tooling costs are major challenges encountered during the turning process. Therefore, optimum machining parameters suitable for turning operations must be selected in other to obtain the desired quality of the finished product at reduced machining time and cost. The present study was carried out on AISI 1018 low carbon steel during turning operation to reduce tooling costs as a result of tool wear and achieve optimum metal removal rate. Taguchi technique was employed using the $L_{9}$ orthogonal array and the analysis of variance (ANOVA) to investigate the effect of the turning parameters on Metal Removal Rate (MRR) and Tool Wear Rate (TWR). The LARGER THE BETTER signal to noise (S/N) ratio based on the Taguchi technique was applied for MRR while the LOWER THE BETTER S/N ratio was applied for TWR. The results revealed that depth of cut is the most significant process parameter for MRR with a percentage contribution of $86.84 \%$; the cutting speed and the feed rate are the most significant process parameters for TWR with percentage contributions of $60.86 \%$ and $33.03 \%$ respectively. The study concludes that AISI 1018 low carbon steel has a maximum MRR of $35.29 \mathrm{~mm}^{3} / \mathrm{s}$ and a minimum TWR of $0.21 \mathrm{~mm} / \mathrm{s}$.
\end{abstract}

Keywords: Orthogonal array, Robust design, Tool wear rate, Metal removal rate

\section{INTRODUCTION}

A good surface finish, reduced machining and tooling costs are the key considerations during machining. A good surface finish is necessary to improve the corrosion resistance, fatigue strength, and aesthetics of the finished product. The MRR and TW Rare very important factors in the machining process and have effect on the machining and tooling costs during turning operation. To increase productivity and reduce machining and tooling costs the engineer needs to select optimum process parameters during turning. Optimization aims at enhancing the performance of a system, part or component while satisfying the desired constraints and is achieved by optimizing the process parameter, thus obtaining the desired finish.

There are many studies on optimization of process parameters to achieve desired surface finish at reduced machining costs. A method of coupling artificial neural network and use of improved harmony search algorithm to determine the optimum cutting parameter settings necessary for minimizing surface roughness when turning polyamide materials was reported [1]. Response Surface Methods (RSM) were employed to evaluate the effect of material removal rate, electrode wear rate and surface roughness in die sinking EDM with hollow tool [2].

A parametric study and optimization of the wire electric discharge machining (WEDM) parameters for CK 45 steel using the response surface methodology was conducted and reported [3]. The Taguchi technique have been employed in optimization during machining process using different parameters and quality characteristics as reported in [4]-[12]. A thorough review of the various optimization techniques employed in determining the process parameters in milling was presented [13]. The effects of machining parameters during CNC turning of AISI 
1018 mild steel using the Graph theoretical model was investigated [14]. The effects of each input parameter on output responses using analysis of variance (ANOVA) were investigated and the responses modelled using regression analysis [15]. A multiobjective optimization of turning parameters was conducted using the combined Multi-objective optimization by ratio analysis (MOORA) and entropy method [16].

This work concentrates on finding the optimum parameter settings for machining of AISI 1018 low carbon steeling other to achieve better metal removal and tool wear rates. The parameters considered are the cutting speed, feed rate and depth of cut.

\section{METHODOLOGY}

The method employed in this study is a mix of both traditional and experimental design methods of Taguchi technique used to optimize the MRR and TWR of the AISI 1018low carbon steel during the turning operation on the lathe.

\subsection{Materials}

The work piece material is the AISI 1018 low carbon steel (LCS) rod with a cross sectional diameter of 70 $\mathrm{mm}$ and length of $600 \mathrm{~mm}$ and chemical composition as shown in Table 1 . The cutting tool material used for the turning operation is the AISI T- $42, \mathrm{CT}, \mathrm{S}-400$, $3 / 8$ " $x 4$ " single point HSS tool with hardness value 67HRC and chemical composition as shown in Table 2. The HSS tool chosen can withstand higher feed rates as a result of its hardness.

The lathe machine (D $360 \times 1000)$ equipped with a variable spindle speed of $1800 \mathrm{rpm}$ and a $4 \mathrm{KW}$ motor drive was used for the turning operation. A center hole was drilled on the face of the work piece to allow for support at the tailstock. The work piece was trued centered and cleaned by removing a $0.2 \mathrm{~mm}$ of the top of the surface, prior to the actual machining tests to eliminate any surface defects and wobbling. The initial cutting parameters used were cutting speed $70 \mathrm{~m} / \mathrm{min}$; feed rate $0.1 \mathrm{~mm} / \mathrm{rev}$; and depth of cut $0.5 \mathrm{~mm}$. The three levels chosen made it easy to study the non-linearity effects.

\section{Table 1: Chemical composition of AISI 1018 low carbon} steel

\begin{tabular}{ll}
\hline Element & Content \% \\
\hline Carbon, C & $0.14-0.20$ \\
Iron, Fe & $98.81-99.26$ \\
Manganese, Mn & $0.60-0.90$ \\
Phosphorus, P & $\leq 0.040$ \\
Sulphur, S & $\leq 0.050$ \\
\hline
\end{tabular}

Table 2: Chemical composition of AISI T-42 CT HSS Tool

\begin{tabular}{ll}
\hline Element & Content \% \\
\hline Carbon, C & 1.43 \\
Chromium, Cr & 3.92 \\
Molybdenum, Mo & 3.56 \\
Tungsten, W & 8.56 \\
Vanadium, V & 2.90 \\
Cobalt, Co & 9.45 \\
\hline
\end{tabular}

Table 3: Experimental outlay and variable sets for TWR and $M R R$

\begin{tabular}{llllll}
\hline & & & \multicolumn{3}{c}{ LEVELS } \\
\hline S/N & Parameters & Units & 1 & 2 & 3 \\
1 & A: Cutting & Rpm & 70 & 110 & 140 \\
& speed & & & & \\
2 & B: Feed rate & $\mathrm{mm} / \mathrm{rev}$ & 0.10 & 0.20 & 0.30 \\
3 & C: Depth of cut & $\mathrm{Mm}$ & 0.50 & 0.75 & 1.00 \\
\hline
\end{tabular}

\subsection{Method}

The Taguchi robust design technique requires a reduction in the process variation through robust design of experiments. The principal objective of the method is to develop high quality product at very low cost to the manufacturer [10].In summary, the steps involved in optimizing the quality of a product using Taguchi approach are:

1. Identification of the objective of the experiment

2. Identification of the performance measures and its measurement

3. The characteristic of performance and their levels

4. Selection of orthogonal array and its allotment to the factors at their levels of the orthogonal array.

5. Testing for the trials in the orthogonal array.

6. Analysis of the experimental data using the signalto-noise ratio

7. Verification of the optimal design parameters through confirmation experiment.

The Experimental outlay and variable sets for tool wear rate and metal removal rate is shown in Table 3.The LARGER THE BETTER signal to noise $(\mathrm{S} / \mathrm{N})$ ratio based on the Taguchi robust design technique was applied for MRR while the LOWER THE BETTER $\mathrm{S} / \mathrm{N}$ ratio was applied for TWR using the quality characteristics and choosing three factor levels $(1,2$, 3) for an $L_{9}\left(3^{3}\right)$ orthogonal array design matrix as shown in Table 4 . The calculated $\mathrm{S} / \mathrm{N}$ ratios for the quality characteristics were evaluated and optimum control factor levels were determined for the parameters. The experiments were done to investigate the relation between the process parameters and response factor. The Minitab 16 software was employed in this study. Results of the experiment were further analyzed using ANOVA. 
Table 4 Applicable Taguchi standard orthogonal array $L_{9}$

\begin{tabular}{llll}
\hline Experiment & Parameter & Parameter & Parameter \\
Number & 1: A & 2: B & 3: C \\
\hline 1 & 1 & 1 & 1 \\
2 & 1 & 2 & 2 \\
3 & 1 & 3 & 3 \\
4 & 2 & 1 & 2 \\
5 & 2 & 2 & 3 \\
6 & 2 & 3 & 1 \\
7 & 3 & 1 & 3 \\
8 & 3 & 2 & 1 \\
9 & 3 & 3 & 2 \\
\hline
\end{tabular}

\subsection{Metal removal rate (MRR)}

The metal removal rate (MRR) in turning operations is the volume of material/metal that is removed per unit time in $\mathrm{mm}^{3} / \mathrm{min}$. For each revolution of the work piece, a ring shaped layer of material is removed. The MRR is mathematically expressed as $[6,17]$ :

$$
M R R=\frac{W_{i}-W_{f}}{\rho t}\left(\frac{m m^{3}}{\min }\right)
$$

In (1), $W_{i}$ is the weight of workpiece in grams before turning; $W_{f}$ is the weight of workpiece in grams after turning; $t$ is the machining time and $\rho$ is the density of mild steel. For the low carbon steel used in this study; $\rho=7.8 \times 10^{-3} \mathrm{gm} / \mathrm{mm}^{3}$

\subsection{Tool Wear Rate}

Tool wear rate in machining is defined as the amount of volume loss of tool material on the contact surface due to the interactions between the tool and work piece. Mathematically, it is expressed as [17]:

$$
T W R=\frac{T_{i}-T_{f}}{t} \quad(\mathrm{~mm} / \mathrm{s})
$$

In (2), $T_{i}$ is the length of cutting tool before turning; $T_{f}$ is the length of cutting tool after turning and $t$ is the time taken for each experiment.

\section{RESULTS AND DISCUSSION}

\subsection{Analysis of Signal to Noise Ratio}

Tables 5 and 6 show the computations for the quality characteristics (MRR and TWR) which were each carried out for three minutes with their respective signal to noise ratios which are aimed at minimizing quality characteristic variations due to uncontrollable parameter. The signal to noise ratio used for MRR and TWR are THE LARGER THE BETTER and THE LOWER
THE BETTER respectively. These are expressed mathematically below:

The $\mathrm{S} / \mathrm{N}$ ratio for THE LARGER THE BETTER is:

$$
S / N=-10 \log _{10} \frac{1}{n} \sum \frac{1}{y^{2}}
$$

The $\mathrm{S} / \mathrm{N}$ ratio for THE LOWER THE BETTER is:

$$
S / N=-10 \log _{10} y^{2}
$$

In (4), $n$ is the number of measurements in a row and $y$ is the value in the row. The $\mathrm{S} / \mathrm{N}$ ratio are determined by taking into consideration equations (3) and (4). Table 7 shows the Taguchi orthogonal array setting and design matrix used for the LARGER THE BETTER $\mathrm{S} / \mathrm{N}$ ratio for MRR and the LOWER THE BETTER S/N ratio for TWR respectively.

The mean responses associated with the dependent variables of this study were also evaluated and presented in tables 8 - 10. The evaluation of mean responses is depicted graphically and they show the factors that are statistically significant in the orthogonal array. This is achieved by separating the effect of each factor by examining the control matrix of table 7 and determining the average $\mathrm{S} / \mathrm{N}$ ratios and mean responses for each factors at each of the three levels as outlined in tables 8-10 and summarized in table 11. The range (Delta) is the difference between high and low response. The larger the (Delta) value for a parameter, the larger effect the variable has on the response factor. This is due to the fact that the same change in signal causes a larger effect on the output variable being measured. Figure 1 depicts the main effects plot means for tool wear rate (TWR).

Figure 2 shows that for the low carbon steel, the TWR increases with increase in cutting speed and decreases with increase in depth of cut and the rate of feed. Figure 3 show the main effects plot for means of metal removal rate (MRR). In figure 4, it was observed that the MRR increases with increase in cutting speed, increase in feed rate and increase in depth of cut. Table 11 and 12 shows the evaluated response and their rankings for the response factors based on the qualities of the larger the better for MRR and the lower the better for TWR; and also for response mean values. Figure 5 shows the SEM micrograph of the AISI 1018 low carbon steel. 
Effect of Turning Parameters on Metal Removal and Tool Wear Rates of Aisi 1018 Low Carbon Steel, $\quad$ C. Mgbemena, et al

Table 5: Experimental design matrix of metal removal rate for AISI 1018LCS

\begin{tabular}{cccccccc}
\hline $\begin{array}{c}\text { Experiment } \\
\text { No. }\end{array}$ & $\begin{array}{c}\text { A: Cutting } \\
\text { Speed }\end{array}$ & B:Feed rate & $\begin{array}{c}\text { C: Depth of } \\
\text { cut }\end{array}$ & $\boldsymbol{W}_{\boldsymbol{i}}$ & $\boldsymbol{W}_{\boldsymbol{f}}$ & $\boldsymbol{M} \boldsymbol{R} \boldsymbol{R}$ & S/N ratio (dB) \\
\hline 1 & 70 & 0.10 & 0.50 & 173 & 156 & 12.108 & 21.6614 \\
2 & 70 & 0.20 & 0.75 & 170 & 137 & 23.504 & 27.4228 \\
3 & 70 & 0.30 & 1.00 & 174 & 131 & 30.627 & 29.7221 \\
4 & 110 & 0.10 & 0.75 & 175 & 143 & 22.792 & 27.1556 \\
5 & 110 & 0.20 & 1.00 & 177 & 134 & 30.627 & 29.7221 \\
6 & 110 & 0.30 & 0.50 & 172 & 158 & 9.972 & 19.9756 \\
7 & 140 & 0.10 & 1.00 & 176 & 133 & 30.627 & 29.7221 \\
8 & 140 & 0.20 & 0.50 & 173 & 152 & 14.957 & 23.4969 \\
9 & 140 & 0.30 & 0.75 & 175 & 128 & 33.476 & 30.4947 \\
\hline
\end{tabular}

Table 6: Experimental design matrix of tool wear rate for AISI 1018LCS

\begin{tabular}{cccccccc}
\hline \multirow{2}{*}{ Expt. No } & $\begin{array}{c}\text { A: } \\
\text { Cutting } \\
\text { Speed }\end{array}$ & $\begin{array}{c}\text { B: } \\
\text { rate }\end{array}$ & $\begin{array}{c}\text { C:Depth } \\
\text { of cut }\end{array}$ & $\boldsymbol{T}_{\boldsymbol{i}}$ & $\boldsymbol{T}_{\boldsymbol{f}}$ & $\boldsymbol{T} \boldsymbol{W} \boldsymbol{R}$ & $\boldsymbol{S} / \boldsymbol{N}$ ratio(dB) \\
\hline 1 & 70 & 0.10 & 0.50 & 0.70 & 0.55 & 0.25 & 12.0412 \\
2 & 70 & 0.20 & 0.75 & 0.81 & 0.40 & 0.41 & 7.7443 \\
3 & 70 & 0.30 & 1.00 & 0.69 & 0.37 & 0.32 & 8.8970 \\
4 & 110 & 0.10 & 0.75 & 0.71 & 0.40 & 0.31 & 10.1728 \\
5 & 110 & 0.20 & 1.00 & 0.72 & 0.27 & 0.45 & 6.9357 \\
6 & 110 & 0.30 & 0.50 & 0.67 & 0.26 & 0.41 & 7.7443 \\
7 & 140 & 0.10 & 1.00 & 0.64 & 0.31 & 0.33 & 9.6297 \\
9 & 140 & 0.20 & 0.50 & 0.71 & 0.21 & 0.50 & 6.0206 \\
\hline
\end{tabular}

Table 7: Estimated quality characteristics, $S / N$ ratios and orthogonal array setting for assessment of mean responses of MRR and TWR of AISI 1018LCS

\begin{tabular}{cccccccc}
\hline $\begin{array}{c}\text { Expt. } \\
\text { No }\end{array}$ & A & B & C & Mean MRR & $\begin{array}{c}\text { S/N ratio of } \\
\text { MRR }\end{array}$ & $\begin{array}{c}\text { Mean TWR } \\
\text { TWR }\end{array}$ \\
\hline 1 & 1 & 1 & 1 & 12.108 & 21.6614 & 0.25 & 12.0412 \\
2 & 1 & 2 & 2 & 23.504 & 27.4228 & 0.41 & 7.7443 \\
3 & 1 & 3 & 3 & 30.627 & 29.7221 & 0.32 & 8.8970 \\
4 & 2 & 1 & 2 & 22.792 & 27.1556 & 0.31 & 10.1728 \\
5 & 2 & 2 & 3 & 30.627 & 29.7221 & 0.45 & 6.9357 \\
6 & 2 & 3 & 1 & 9.972 & 19.9756 & 0.41 & 7.7443 \\
7 & 3 & 1 & 3 & 30.627 & 29.7221 & 0.33 & 9.6297 \\
8 & 3 & 2 & 1 & 14.957 & 23.4969 & 0.50 & 6.0206 \\
9 & 3 & 3 & 2 & 33.476 & 30.4947 & 0.51 & 5.8486 \\
\hline
\end{tabular}

Table 8: Average responses obtained for MRR and TWR for cutting speed (A) at level 1, 2 and 3 within experiments 1 to 9

\begin{tabular}{ccccc}
\hline S/No. & $\begin{array}{c}\text { Quality characteristic } \\
\text { factor level }\end{array}$ & $\begin{array}{c}\text { Average of response for } \\
\text { different level }\end{array}$ & Response value for MRR & $\begin{array}{c}\text { Response value for } \\
\text { TWR }\end{array}$ \\
\hline 1 & $M m s_{1}$ & $\left(a_{1}+a_{2}+a_{3} / 3\right)$ & 22.08 & 0.3267 \\
2 & $\left(S / N_{a v 1}\right)$ & $\left(a_{1}+a_{2}+a_{3} / 3\right)$ & 26.27 & 9.894 \\
3 & $M m s_{2}$ & $\left(a_{4}+a_{5}+a_{6} / 3\right)$ & 21.13 & 0.3900 \\
4 & $\left(S / N_{a v 2}\right)$ & $\left(a_{4}+a_{5}+a_{6} / 3\right)$ & 25.62 & 8.284 \\
5 & $M m s_{2}$ & $\left(a_{7}+a_{8}+a_{9} / 3\right)$ & 26.35 & 0.4467 \\
6 & $\left(S / N_{a v 3}\right)$ & $\left(a_{7}+a_{8}+a_{9} / 3\right)$ & 27.90 & 7.166 \\
\hline
\end{tabular}

Table 9: Average responses obtained for MRR and TWR for Feed rate (B) at level 1, 2 and 3 within experiments 1 to 9

\begin{tabular}{ccccc}
\hline S/No. & Quality characteristic & $\begin{array}{c}\text { Average of response for } \\
\text { different level }\end{array}$ & $\begin{array}{c}\text { Response value for } \\
\text { TWR }\end{array}$ & $\begin{array}{c}\text { Response value for } \\
\text { MRR }\end{array}$ \\
\hline 1 & $\left(M m s_{1}\right)$ & $\left(b_{1}+b_{4}+b_{7} / 3\right)$ & 0.2967 & 21.84 \\
2 & $\left(S / N_{a v 1}\right)$ & $\left(b_{1}+b_{4}+b_{7} / 3\right)$ & 10.615 & 26.18 \\
3 & $\left(M s_{2}\right)$ & $\left(b_{2}+b_{5}+b_{8} / 3\right)$ & 0.4533 & 23.03 \\
4 & $\left(S / N_{a v 2}\right)$ & $\left(b_{2}+b_{5}+b_{8} / 3\right)$ & 6.900 & 26.88 \\
5 & $\left(M m s_{2}\right)$ & $\left(b_{3}+b_{6}+b_{9} / 3\right)$ & 0.4133 & 24.69 \\
6 & $\left(S / N_{a v 3}\right)$ & $\left(b_{3}+b_{6}+b_{9} / 3\right)$ & 7.830 & 26.73 \\
\hline
\end{tabular}


Table 10: Average responses obtained for MRR and TWR for depth of cut (C) at Level 1, 2 and 3 within experiments 1to 9

\begin{tabular}{|c|c|c|c|c|}
\hline S/No. & $\begin{array}{c}\text { Quality } \\
\text { characteristic }\end{array}$ & $\begin{array}{l}\text { Average of response for } \\
\text { different level }\end{array}$ & $\begin{array}{c}\text { Response value for } \\
\text { TWR }\end{array}$ & $\begin{array}{c}\text { Response value for } \\
\text { MRR }\end{array}$ \\
\hline 1 & $\left(M m s_{1}\right)$ & $\left(c_{1}+c_{6}+c_{87} / 3\right)$ & 0.3867 & 12.35 \\
\hline 2 & $\left(S / N_{a v 1}\right)$ & $\left(c_{1}+c_{6}+c_{87} / 3\right)$ & 8.602 & 21.71 \\
\hline 3 & $\left(M m s_{2}\right)$ & $\left(c_{2}+b_{4}+c_{9} / 3\right)$ & 0.4100 & 26.59 \\
\hline 4 & $\left(S / N_{a v 2}\right)$ & $\left(c_{2}+b_{4}+c_{9} / 3\right)$ & 7.922 & 28.36 \\
\hline 5 & $\left(M m s_{2}\right)$ & $\left(c_{3}+c_{5}+c_{7} / 3\right)$ & 0.3667 & 30.63 \\
\hline 6 & $\left(S / N_{a v 3}\right)$ & $\left(c_{3}+c_{5}+c_{7} / 3\right)$ & 8.821 & 29.72 \\
\hline
\end{tabular}

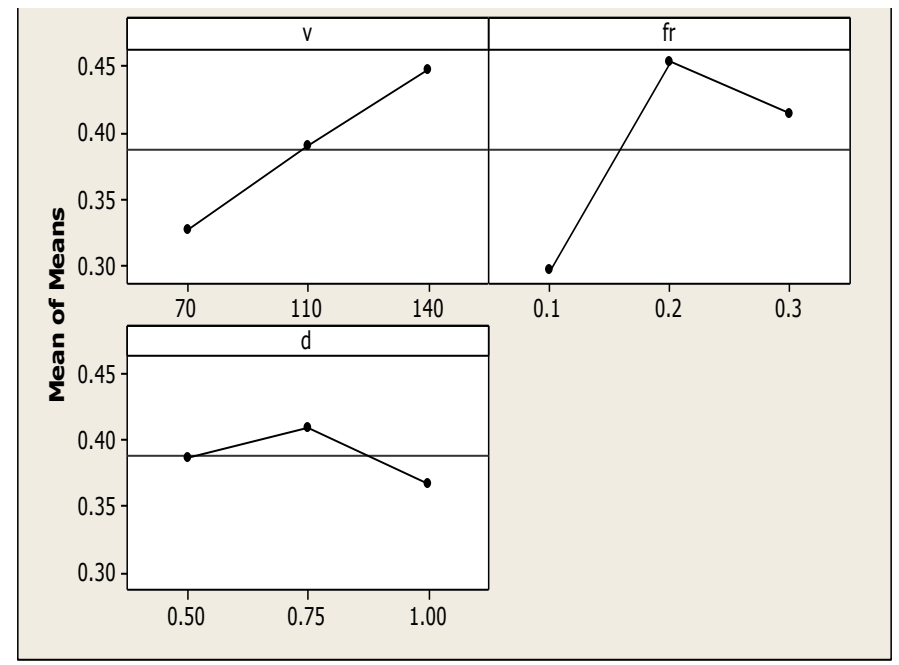

Figure 1: Main effects plot means for tool wear rate (TWR)

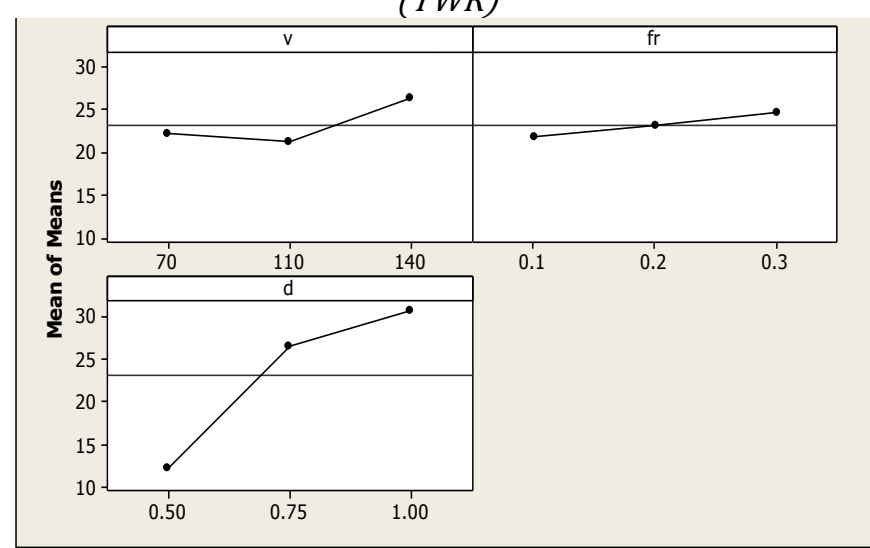

Figure 3: Main effects plot for means of metal removal rate $(M R R)$

Table 11: Summary of responses and rankings for TWR of AISI 1018 low carbon steel

\begin{tabular}{cccc}
\hline \multirow{2}{*}{$\begin{array}{c}\text { Response } \\
\text { Level }\end{array}$} & $\begin{array}{c}\text { A: Cutting } \\
\text { speed }\end{array}$ & B: Feed rate & $\begin{array}{c}\text { C: Depth of } \\
\text { cut }\end{array}$ \\
\cline { 2 - 4 } 1 & 9.894 & 10.615 & 8.602 \\
2 & 8.284 & 6.900 & 7.922 \\
3 & 7.166 & 7.830 & 8.821 \\
Delta & 2.728 & 3.714 & 0.899 \\
Rank & 2 & 1 & 3 \\
\hline \multicolumn{4}{c}{ Means } \\
\hline 1 & 0.3267 & 0.2967 & 0.3867 \\
2 & 0.3900 & 0.4533 & 0.4100 \\
3 & 0.4467 & 0.4133 & 0.3667 \\
Delta & 0.1200 & 0.1567 & 0.0433 \\
Rank & 2 & 1 & 3 \\
\hline
\end{tabular}

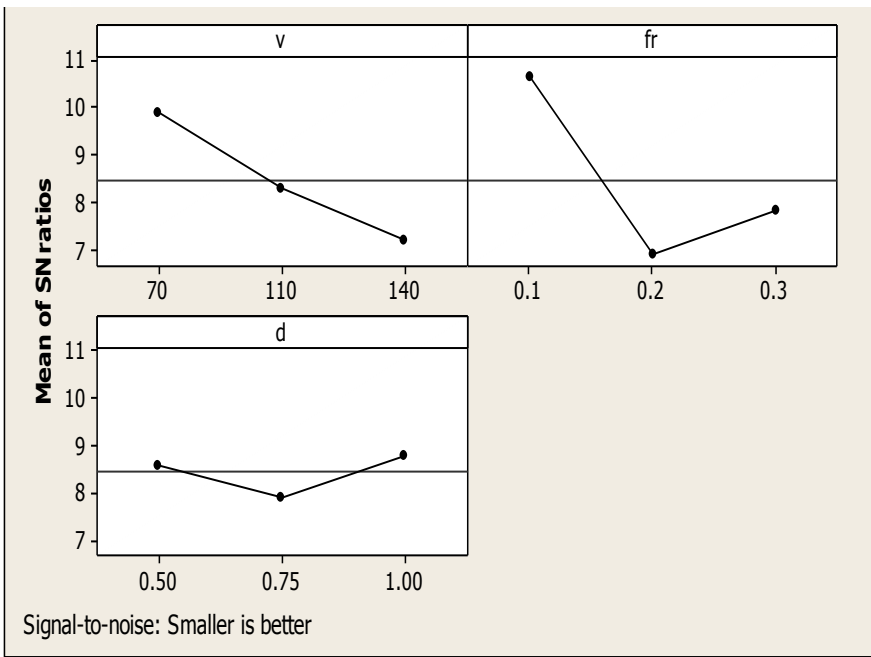

Figure 2: Main effects plot for signal to noise ratio of tool wear rate (TWR)

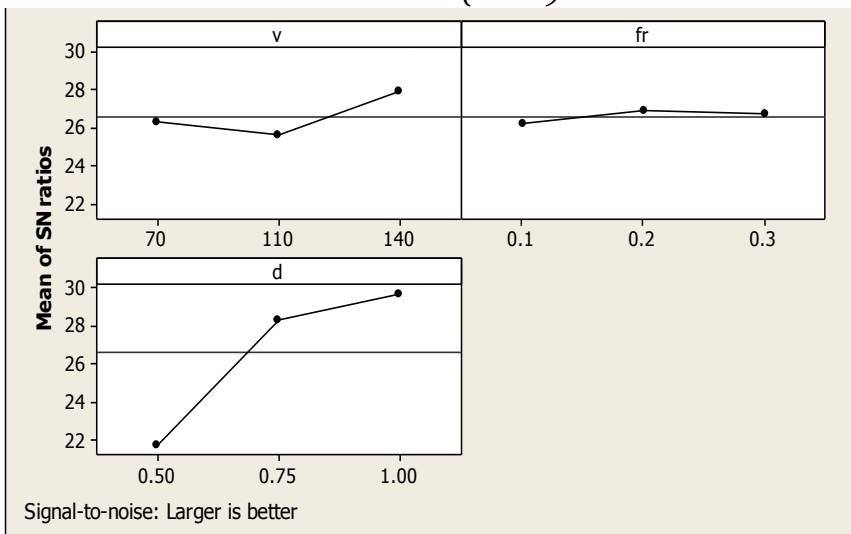

Figure 4: Main effects for means of signal to noise ratio for metal removal rate (MRR)

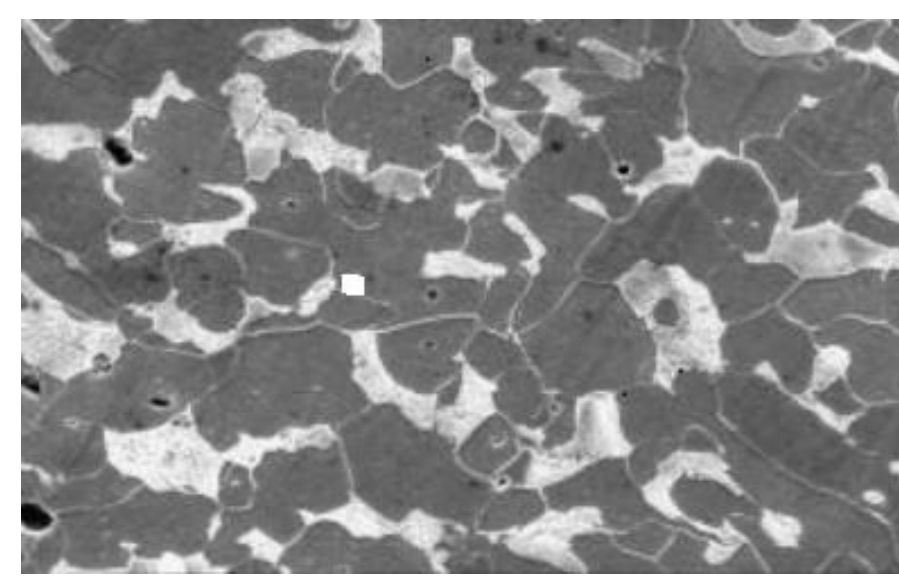


Figure 5SEM Micrograph of AISI 1018 Low Carbon Steel at $600 X$

Table 12: Summary of responses and rankings for MRR of AISI 1018 low carbon steel

\begin{tabular}{cccc}
\hline \multirow{2}{*}{$\begin{array}{c}\text { Response } \\
\text { Level }\end{array}$} & \multicolumn{3}{c}{ Signal to noise ratio } \\
\cline { 2 - 4 } & A: Cutting & B: Feed rate & $\begin{array}{c}\text { C: Depth of } \\
\text { sut }\end{array}$ \\
\hline 1 & 26.27 & 26.18 & 21.71 \\
2 & 25.62 & 26.88 & 28.36 \\
3 & 27.90 & 26.73 & 29.72 \\
Delta & 2.29 & 0.70 & 8.01 \\
Rank & 2 & 3 & 1 \\
\hline & & Means & \\
\hline 1 & 22.08 & 21.84 & 120.35 \\
2 & 21.13 & 23.03 & 26.59 \\
3 & 26.35 & 24.69 & 30.63 \\
Delta & 5.22 & 2.85 & 18.28 \\
Rank & 2 & 3 & 1 \\
\hline
\end{tabular}

\subsection{Analysis of Variance (Anova)}

The aim of the analysis of variance (ANOVA) is to examine which design factors significantly affects the MRR and TWR. The relevance of the machining parameters with respect to MRR and TWR were investigated for the low carbon steel and presented in Tables 13 and 14. The total sum of squared deviations from the $\mathrm{S} / \mathrm{N}$ ratio, $n_{m}$ were evaluated using the equation.

$$
S S_{t}=\sum_{i=1}^{n}\left(n_{i}-n_{m}\right)
$$

In (5), $n$ is the number of experiments in the orthogonal array and $n_{i}$ is the mean signal to noise ratio of the $i^{\text {th }}$ experiment. The percentage contribution $P$ reports the significance level. It can be calculated as:

$$
P=\frac{S S_{d}}{S S_{t}}
$$

Here $S S_{d}$ is the sum of the squared deviation.

The Fisher test (F-test) is employed to statistically identify which parameters have significant effect on the quality characteristics. In this study, the $\mathrm{F}$ ratio is the ratio of the mean squared error to the residual error and is used to determine the significance of a factor.

The sources with values less than 0.1 (i.e. for a confidence level of $90 \%$ ) were considered to have statistical significant contribution to the performance measures. The depth of cut with a percentage of $86.84 \%$ is the parameter with significant effect on metal removal rate (MRR). Similarly, the significant factors that affect the tool wear rate (TWR) of LCS in this experiment are the cutting speed and the feed rate as shown in Table 14.

\subsection{Estimation of Expected Responses and Confirmation of Experiments}

The estimation of the expected responses and confirmation of experiment is the final stage in the Taguchi robust design. The confirmation of experiment is used to confirming the inference drawn during the analysis phase. For conducting the confirmation experiments, the optimum conditions are set for significant parameters and a designated number of experiments are carried out under specified conditions. The mean of the confirmation experiments result is compared with the estimated average based on the parameters and levels tested.

The expected response is estimated using the optimum control factor settings from the main effect plot; by employing the response table for $\mathrm{S} / \mathrm{N}$ ratio and the response table for mean [11].

Table 13: ANOVA results for MRR of AISI 1018LCS

\begin{tabular}{lllllllll}
\hline Source & DOF & Seq. SS & Adj SS & Adj MS & F & P & C (\%) & Status \\
\hline A:Cutting Speed & 2 & 46.45 & 46.45 & 23.22 & 1.85 & 0.351 & & Insignificant \\
B:Feed Rate & 2 & 12.29 & 12.29 & 6.15 & 0.49 & 0.672 & & Insignificant \\
C:Depth of cut & 2 & 553.42 & 553.42 & 276.71 & 22.01 & 0.043 & 86.84 & Significant \\
Error & 2 & 25.14 & 25.14 & 12.57 & & & & \\
\hline Total & 8 & 637.29 \\
\hline \multicolumn{7}{c}{$S=3.5434 ; R-s q=96.06 \% ; R-s q($ adj $)=84.22 \%$} & &
\end{tabular}

Table 14: ANOVA results for TWR of AISI 1018LCS

\begin{tabular}{lllllllll}
\hline Source & DOF & Seq. SS & Adj. SS & Adj MS & F & P & C (\%) & Status \\
\hline A:Cutting Speed & 2 & 0.0216 & 0.0216 & 0.0108 & 18.71 & 0.051 & 33.03 & Significant \\
B:Feed Rate & 2 & 0.0398 & 0.0398 & 0.0198 & 34.40 & 0.028 & 60.86 & Significant \\
C:Depth of cut & 2 & 0.0028 & 0.0028 & 0.0014 & 2.44 & 0.291 & 4.28 & Insignificant \\
Error & 2 & 0.0012 & 0.0012 & 0.0006 & & & & \\
\hline Total & 8 & 0.0654 & 0.0654 & & & & \\
\hline \multicolumn{7}{c}{$S=0.2430 ; R-s q=98.23 \% ; R-s q=98.23 \%$} &
\end{tabular}


The expected response model is as in equation (6) and the result is shown in table 15 .

$$
\begin{gathered}
E_{r}=A V_{r}+\left(a_{o p t}-A V_{r}\right)+\left(b_{o p t}-A V_{r}\right) \\
+\left(c_{o p t}-A V_{r}\right)
\end{gathered}
$$

In (6), $E_{r}$ is the expected response; $A V_{r}$ is the average response; $a_{o p t}$ is the mean value of setting at optimum setting of factor $a$; $b_{\text {opt }}$ is the mean value of setting at optimum setting of factor $\mathrm{b}$ and $c_{\text {opt }}$ is the mean value of setting at optimum setting of factor $\mathrm{c}$.

Table15: Optimum settings of control factors and

\begin{tabular}{|c|c|c|c|}
\hline Response & $\begin{array}{l}\text { Control } \\
\text { Factor }\end{array}$ & $\begin{array}{c}\text { Optimum } \\
\text { Setting }\end{array}$ & $\begin{array}{c}\text { Expected } \\
\text { optimum strength }\end{array}$ \\
\hline \multirow{3}{*}{ MRR } & A & 140 & \multirow{3}{*}{35.2944} \\
\hline & B & 0.30 & \\
\hline & C & 0.75 & \\
\hline \multirow{3}{*}{ TWR } & A & 140 & \multirow{3}{*}{0.2145} \\
\hline & B & 0.30 & \\
\hline & C & 0.75 & \\
\hline
\end{tabular}
expected optimum strength

\section{CONCLUSION}

From this study, the following conclusion were drawn:

1. From the ANOVA, it was found that depth of cut is the most important parameter for MRR. The most important parameters for TWR were found to be the cutting speed and feed. It is therefore important to employ suitable combinations of cutting speed, feed and depth of cut to reduce the variations that can affect the quality of the work piece and the cutting tool.

2. The signal to noise(S/N) ratio showed that for tool wear rate, the optimal machining condition was obtained at a cutting speed of $140 \mathrm{rpm}$, a feed of $0.30 \mathrm{~mm} / \mathrm{rev}$ and a depth of $0.75 \mathrm{~mm}$. For metal removal rate, the optimal machining condition was obtained at a cutting speed of $140 \mathrm{rpm}$, a feed of $0.30 \mathrm{~mm} / \mathrm{rev}$ and a depth of $0.75 \mathrm{~mm}$.

3. The AISI 1018 LCS has an improved MRR with a value of $35.29 \mathrm{~mm}^{3} / \mathrm{s}$ during turning operation when the control factors(cutting speed, feed rate and depth of cut) are $140 \mathrm{rpm}, 0.3 \mathrm{~mm} / \mathrm{rev}$ and $0.75 \mathrm{~mm}$ respectively. Similarly,AISI $1018 \mathrm{LCS}$ rod has an improved TWR with a value of $0.21 \mathrm{~mm} / \mathrm{s}$.

\section{REFERENCES}

[1] Madic, M., Markoic, D and Radovanovic, M. "Application of surface roughness when turning polyamide using ANN-IHSA approach". International Journal of Engineering and
Technology, Vol. 1 Number 4, (2012), pp 432-443. 2012.

[2] Teepu, S., Anish, K., and Rahul, D. G. "Material Removal Rate, Electrode Wear Rate, and Surface Roughness Evaluation in Die Sinking EDM with Hollow Tool through Response Surface Methodology". International Journal of Manufacturing Engineering, doi:10.1155/2014/ 259129. 2014.

[3] El-Tawaleel, T. A and Hewidy, A. M." Parametric study and optimization of WEDM parameters for CK 45 Steel, International Journal of Engineering Practical Research, Vol 2, Number 4, , pp 156-169. 2013.

[4] Kanase, T., and Jadhav, D. B."Enhancement of surface finish for CNC turning cutting parameters by using Taguchi method". Indian Journal of Research, Vol. 3, Number 5, (2013), pp 88-91. 2013.

[5] Ajay, M and Anshul, G. "Application of Taguchi method in optimization of tool flank wear width in turning operation of AISI 1045 steel". Industrial Engineering Letters, Vol. 2, Number 8, , pp 11-18. 2012.

[6] Dave, H., Patel, L. and Raval, H."Effect of machining conditions on MRR and surface roughness during CNC turning of different materials using TiN coated cutting tools: A Taguchi approach". International Journal of Industrial Engineering Computations Vol. 3, , pp 925-930. 2012.

[7] Hassan, K., Anish, K., and Garg, M.,. "Experimental investigation of material removal rate in CNC turning using Taguchi method".International Journal of Engineering Research and Applications, Vol 2, Number 2, 2012, pp 1581-1590. 2012.

[8] Kaladhar, M., Subbaiah, K and Rao, C. "Parametric optimization during machining of AISI 304 Austenitic Stainless Steel using CVD coated DURATOMIC cutting insert". International Journal of Industrial Engineering Computations, Vol 3, Number 4, pp 577-586. 2012.

[9] Adinarayana, M., Prasanthi, G. and Krishnaiah, G. "Parametric analysis and multi-objective optimization of cutting parameters in turning operation of AISI 434 Alloy Steel with CVD Cutting Tool". International Journal of Research in Engineering andTechnology, Vol. 3, Number 2, ,pp 449-456. 2014.

[10] Quazi T. Z, More P., and Sonawane, V."A case study of Taguchi method in the optimization of turning parameters". International journal of Emerging Technology and Advanced Engineering, Vol. 3, Number2, ,pp 616-626. 2013.

[11] Okonkwo, U., Chukwunyelu, C., Oweziem, B. and Ekuase, A. "Evaluation and Optimization of Tensile Strength Responses of Coir Fibres Reinforced 
Polyester Matrix Composites (CFRP) Using Taguchi Robust Design", Journal of Minerals and Materials Characterization and Engineering, Vol. 3, 2015, pp 225-236. Doi:10.4236/jmmce..34025, 2015.

[12] Okafor, E. C., Ihueze, C. C. and Nwigbo S.C. "Optimization of Hardness Strengths Response of Plantain Fibres Reinforced Polyester Matrix Composites (PFRP) Applying Taguchi Robust Design", International Journal of Engineering, Vol. 26, Number 1, pp 1-12. 2013.

[13] Sengar, D. and Sarathe, A.K. "Optimization of Milling machining process parameters: A review", International Journal of Engineering Sciences and Research Technology, , vol. 1 Number.1, pp 79-89. 2016.

[14] Jangra, S., Gupta, M., and Kumar, R. "Analysis of the effects of parameters on mild steel (1018) during CNC turning using Graph Theory", International
Journal of Engineering Science and Computing, 2016, Vol.6, Number 5, pp 5869-5873. doi:10.4010/.1424. 2016.

[15] Singh, B. K., Mondal, B., and Mandal, N. "Machinability evaluation and desirability function optimization of turning parameters for $\mathrm{Cr} 203$ doped zirconia toughened alumina (Cr-ZTA) cutting insert in high speed machining of steel," Ceram. Int., vol. 42, pp. 3338-3350, 2015.

[16] Singaravel, B., Selvaraj, T., and Vinodh, S. "MultiObjective Optimization of Turning Parameters Using the Combined Moora and Entropy Method," Trans. Can. Soc. Mech. Eng., Vol. 40, no. 1, 2016.

[17] Kumar, U., Singh, A., and Kumar, R. "Optimization of Machining Parameters for Tool Wear Rate and Material Removal Rate in CNC turning by Grey Relational Analysis," Int. J. Appl. Eng. Res. ISSN, vol. 11, no. 4, pp. 973-4562, 2016. 